\title{
A Study of K-Factor Power Transformer Characteristics by Modeling Simulation
}

\author{
O. E. Gouda \\ Electric Power and Machines Dpt \\ Cairo University \\ Cairo, Egypt \\ osama241@hotamail.com
}

\author{
G. M. Amer \\ High Institute of Technology \\ Benha University \\ Benha, Egypt \\ ghada.amer@bhit.bu.edu.eg
}

\author{
W. A. A. Salem \\ High Institute of Technology \\ Benha University \\ Benha, Egypt. \\ walid.attia@bhit.bu.edu.eg
}

\begin{abstract}
Harmonic currents generated by nonlinear loads can cause overheating and premature failure in power transformers. K-factor transformers are specially designed to accommodate harmonic currents and offer protection against overheating caused by harmonics. They minimize harmonic current loss and have an additional thermal capacity of known limits. According to IEEE C57-110, the winding eddy current losses are considered proportional to the harmonic current squared times its harmonic number. K-factor is only an indicative value and the authors' main objective in this paper is to study the effect of harmonics on oil filled transformer and to simulate harmonic behavior using Matlab Simulink. A case study is simulated in order to investigate $\mathrm{K}$-factor values with pumping loads, with and without the use of harmonic filters. Results are compared with measured values.
\end{abstract}

Keywords-component; K-factor transformers; harmonics filter; total harmonic distortion

\section{INTRODUCTION}

In recent years, there has been an increased concern about the effects of nonlinear loads on electric power systems [1]. Harmonic currents adversely affect virtually every component in the power system, creating additional dielectric, thermal, and/or mechanical stresses [2]. The harmonic currents flowing through the power system impedances result in harmonic voltage drops which are observed as voltage distortions. Severe voltage distortions may occur when the power system's inductive and capacitive reactance's happen to be equal (parallel resonance) at one of the nonlinear load's significant harmonic current frequencies (typically the 5th, 7th, 11 th or 13th harmonic) [2-5].

Even without resonance, harmonic currents cause losses in normal power system components. Wiring experiences additional heating beyond the normal $\mathrm{I}^{2} \mathrm{R}$, due to skin and proximity effects. Harmonics also cause over heating of the neutral conductor due to the additive nature of triple harmonics (3rd, 9th, 15th, etc.) on three phase four wire systems serving nonlinear loads with line-to-neutral connections [6, 7].

With transformers, harmonic load currents cause additional heating, primarily in the form of additional winding eddy current losses. IEEE C57.110, provides methods to de-rate a transformer for any given harmonic load profile [8].

K-factor transformers are specifically designed to accommodate harmonic currents and they have an additional thermal capacity of known limits, allowing operation up to nameplate capacity without de-rating.

\section{K-FACTOR TRANSFORMERS}

$\mathrm{K}$-factor rating is optionally applied to a transformer, indicating its suitability for use with loads that draw non sinusoidal currents. The $\mathrm{K}$-factor is given by the following equation $[6,9]$.

$$
K-\text { Factor }=\sum_{h=1}^{h=\max } I_{h}^{2} h^{2} \quad(p u)
$$

where:

$\mathrm{h}=$ harmonic number, $\mathrm{I}_{\mathrm{h}}=$ the fraction of total rms load current at harmonic number $h$

$\mathrm{K}$-factor rated transformers have not been evaluated for use with harmonic loads where the rms current of any singular harmonic greater than the tenth harmonic is greater than $1 / \mathrm{h}$ of the fundamental rms current.

\section{A. Relationship between K-factor and harmonic loss factor}

The definition of the K-factor by the Underwriter's Laboratory (UL) [10] is based on using the transformer rated current in the calculation of per unit current in the previous equation. Substituting the rated current for the K-factor gives:

$$
K-\text { Factor }=\sum_{h=1}^{h=\max } h^{2}\left(\frac{I_{h}}{I_{R}}\right)^{2}=\frac{1}{I_{R}^{2}} \sum_{h=1}^{h=\max } I_{h}^{2} h^{2}
$$

where:

$h$ is the harmonic order, $I_{h}$ is the rms current at harmonic " $h$ " (amperes), $I_{R}$ is the rms fundamental current under rated frequency and rated load conditions (amperes).

The relationship of the harmonic loss factor and the UL Kfactor [11-13] is given by:

$$
K-\text { Factor }=\left(\frac{\sum_{h=1}^{h=\max } I_{h}^{2}}{I_{R}^{2}}\right) F_{H L}
$$

The harmonic loss factor is a function of the harmonic current distribution and is independent of the relative magnitude. The UL K-factor is dependent on both the magnitude and the distribution of the harmonic current. For a 
set of harmonic load current measurements, the calculation of the UL K-factor is dependent on the transformer rated secondary current. For a new transformer with harmonic currents specified as per unit of the rated transformer secondary current, the K-factor and harmonic loss factor have the same numerical values. The numerical value of the K-factor equals the numerical value of the harmonic loss factor only when the square root of the sum of the harmonic currents squared equals the rated secondary current of the transformer $[14,15]$.

\section{B. Standard transformers $K$-factor ratings}

The standard K-factor transformer ratings and typical loads are given in Table I [10].

TABLE I. K-FACTOR TRANSFORMER RATINGS

\begin{tabular}{|c|c|}
\hline Load & K-factor \\
\hline $\begin{array}{l}\text { Incandescent lighting (with no solid state dimmers) } \\
\text { Electric resistance heating (with no solid state heat } \\
\text { controls) } \\
\text { Motors (without solid state drives) } \\
\text { Control transformers/electromagnetic control devices } \\
\text { Motor-generators (without solid state drives) }\end{array}$ & $\begin{array}{l}\text { K-1 } \\
\text { K-1 } \\
\text { K-1 } \\
\text { K-1 } \\
\text { K-1 }\end{array}$ \\
\hline $\begin{array}{l}\text { Electric-discharge lighting } \\
\text { UPS w/optional input filtering } \\
\text { Induction heating equipment } \\
\text { Welders } \\
\text { PLC's and solid state controls (other than variable speed } \\
\text { drives) }\end{array}$ & $\begin{array}{l}\text { K-4 } \\
\text { K-4 } \\
\text { K-4 } \\
\text { K-4 } \\
\text { K-4 }\end{array}$ \\
\hline $\begin{array}{l}\text { Telecommunications equipment } \\
\text { UPS without input filtering } \\
\text { Multi-wire receptacle circuits in general care areas of health } \\
\text { care, facilities and classrooms of schools, etc. } \\
\text { Multi-wire receptacle circuits supplying inspection or } \\
\text { testing equipment on an assembly or production line }\end{array}$ & $\begin{array}{l}K-13 \\
K-13 \\
K-13 \\
K-13\end{array}$ \\
\hline $\begin{array}{l}\text { Mainframe computer loads } \\
\text { Solid state motor drives (variable speed drives) } \\
\text { Multi-wire receptacle circuits in critical care areas and } \\
\text { operating/recovery rooms of hospitals }\end{array}$ & $\begin{array}{l}\text { K-20 } \\
\text { K-20 } \\
\text { K-20 }\end{array}$ \\
\hline $\begin{array}{l}\text { Multi-wire receptacle circuits in industrial, medical, and } \\
\text { educational laboratories. } \\
\text { Multi-wire receptacle circuits in commercial office spaces } \\
\text { Small mainframes (mini and micro) }\end{array}$ & $\begin{array}{l}\mathbf{K}-30 \\
\mathbf{K}-30 \\
\mathbf{K}-30\end{array}$ \\
\hline $\begin{array}{l}\text { Other loads identified as producing very high amounts of } \\
\text { harmonics (especially in higher orders) }\end{array}$ & K-40 \\
\hline
\end{tabular}

K-factor transformers are designed to be operated fully loaded with any harmonic load having a $\mathrm{K}$-factor equal to or less than its K-rating. For example, a K-13 transformer can be fully loaded with any harmonic load having a K-factor up to K13. If the load has a K-factor greater than 13 , then the transformer cannot be safely operated at full load and would require de-rating [16].

For K-factor transformers, UL also requires that the neutral terminal and connections be sized to accommodate twice the rated phase conductor size (double the minimum neutral capacity) of standard transformers. Standard transformers, i.e. those not marked with a K-factor rating, may have some tolerance to nonlinear loading [16], but their capability is unknown to the user and is not certified by a third party such as
UL. Currently, marking a transformer with a K-factor rating is not required by UL.

\section{CASE STUDY}

The Toshka Pumping Station was constructed between 1998 and 2003. It is literally the largest state project in Egypt. Located along the shores of the Nasser Lake, which was created by the construction of the famous, Aswan Dam, this pumping station is a project in which Hitachi, Ltd. installed 21 large vertical centrifugal volute pumps with the capacity to draw 29 million cubic meters of water per day and supply it to the desert area. About 2,250 square kilometers of land are to be greened through this project $[17,18]$. A view of the Toshka pumping station is illustrated in Figure 1.

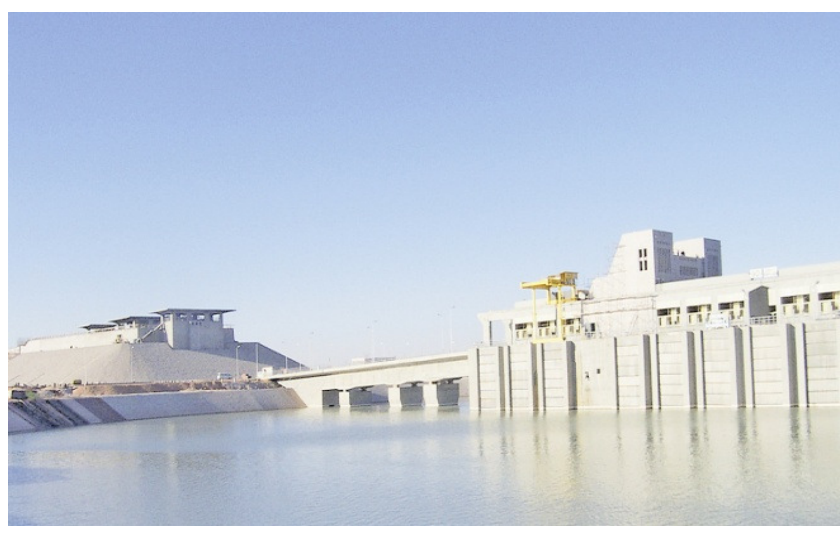

Fig. 1. Toshka Pumping Station

\section{A. Description of Toshka pumping station}

The pumping station, which is located at the intake basin, will accommodate (in the final stage) 24 variable speed pumps with a total capacity of $288 \mathrm{MW}(24 \mathrm{x} 12 \mathrm{MW})$ and a total discharge of $400 \mathrm{~m}^{3} / \mathrm{s}\left(24 \times 16.7 \mathrm{~m}^{3} / \mathrm{s}\right)$. The static suction head is $56 \mathrm{~m}$. The pumping station dimensions are $145 \times 60 \times 45 \mathrm{~m}$ (1 $\mathrm{x} \mathrm{h} \mathrm{x} \mathrm{w).} \mathrm{The} \mathrm{electrical} \mathrm{supply} \mathrm{to} \mathrm{the} \mathrm{plant} \mathrm{is} \mathrm{secured} \mathrm{via} \mathrm{a}$ 220/11KV substation in Toshka and an $11 \mathrm{kV}$ bus duct, which were also supplied by ABB in a separate contract under the Toshka Project. Figure 2 represents the single line diagram of $220 \mathrm{kV}$ substation to $11 \mathrm{kV}$ Toshka pump station.

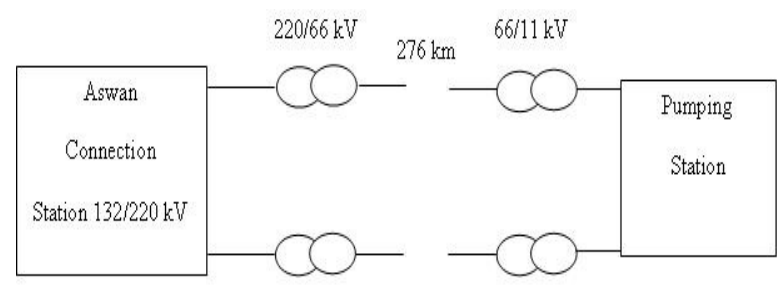

Fig. 2. Connection between Aswan connection substation and Toshka pumping station

\section{B. Measurement Technique}

The harmonics measurement location is shown in Figure 3, the point of common coupling is the most important point of 
harmonics measurement, and it is located on the output of the $66 / 11 \mathrm{kV}, 25 \mathrm{MVA}$ transformers. Measurements of the harmonic currents and K-factor calculations for Toshka pumping station without harmonic filter are shown in Table II and with harmonic filter are shown in Table III. The measurements are carried out on phase B. From the measurement values it is shown that the $\mathrm{K}$-factor for the system without harmonic filter is equal to 5.436679, whereas the Kfactor for the system with harmonic filter is equal to 1.200575 , which means that he use of the harmonic filter decreases the selected $\mathrm{K}$-factor transformer ratings almost five times.

TABLE II. HARMONICS MEASUREMENT WITHOUT FILTER

\begin{tabular}{|c|c|c|c|c|}
\hline $\mathrm{H}$ & $\mathrm{I}_{\mathrm{H}} \%$ fund & $\mathrm{I}_{\mathrm{H}}$ & $\mathrm{I}_{\mathrm{h}}=\mathrm{I}_{\mathrm{H}} / \mathrm{I}_{\mathrm{rms}}$ & $\overline{\mathrm{H}^{2 *}\left(\mathrm{I}_{\mathrm{h}}\right)^{2}}$ \\
\hline 1 & 100 & 1 & 0.996924891 & 0.993859237 \\
\hline 3 & 2.5591 & 0.025591 & 0.025512305 & 0.005857899 \\
\hline 5 & 6.8061 & 0.068061 & 0.067851705 & 0.115096347 \\
\hline 7 & 2.263 & 0.02263 & 0.02256041 & 0.024939633 \\
\hline 9 & 0.12456 & 0.0012456 & 0.00124177 & 0.000124901 \\
\hline 11 & 1.4063 & 0.014063 & 0.014019755 & 0.023782976 \\
\hline 13 & 1.3018 & 0.013018 & 0.012977968 & 0.028464274 \\
\hline 15 & 0.05778 & 0.0005778 & 0.000576113 & $7.46789 \mathrm{E}-05$ \\
\hline 17 & 0.09951 & 0.0009951 & 0.00099208 & 0.00028444 \\
\hline 19 & 0.08968 & 0.0008968 & 0.000894102 & 0.00028859 \\
\hline 21 & 0.05123 & 0.0005123 & 0.000510755 & 0.000115044 \\
\hline 23 & 0.20088 & 0.0020088 & 0.002002623 & 0.002121553 \\
\hline 25 & 0.07366 & 0.0007366 & 0.000734425 & 0.000337112 \\
\hline 27 & 0.05600 & 0.0005600 & 0.000558298 & 0.000227227 \\
\hline 29 & 0.04900 & 0.0004900 & 0.000488563 & 0.000200741 \\
\hline 31 & 0.09088 & 0.0009088 & 0.000906025 & 0.000788867 \\
\hline 33 & 0.04416 & 0.0004416 & 0.000440302 & 0.00021112 \\
\hline 35 & 0.05046 & 0.0005046 & 0.000503138 & 0.000310106 \\
\hline 37 & 0.05041 & 0.0005041 & 0.00050256 & 0.000345763 \\
\hline 39 & 0.04367 & 0.0004367 & 0.000435377 & 0.00028831 \\
\hline 41 & 0.03704 & 0.0003704 & 0.000369321 & 0.000229285 \\
\hline 43 & 0.04254 & 0.0004254 & 0.000424142 & 0.000332628 \\
\hline 45 & 0.04760 & 0.0004760 & 0.000474586 & 0.000456095 \\
\hline 47 & 0.07259 & 0.0007259 & 0.000723728 & 0.001157034 \\
\hline 49 & 0.05342 & 0.000534 & 0.000532647 & 0.000681194 \\
\hline$\sum$ & & & $\mathrm{K}=$ & 1.200575 \\
\hline
\end{tabular}

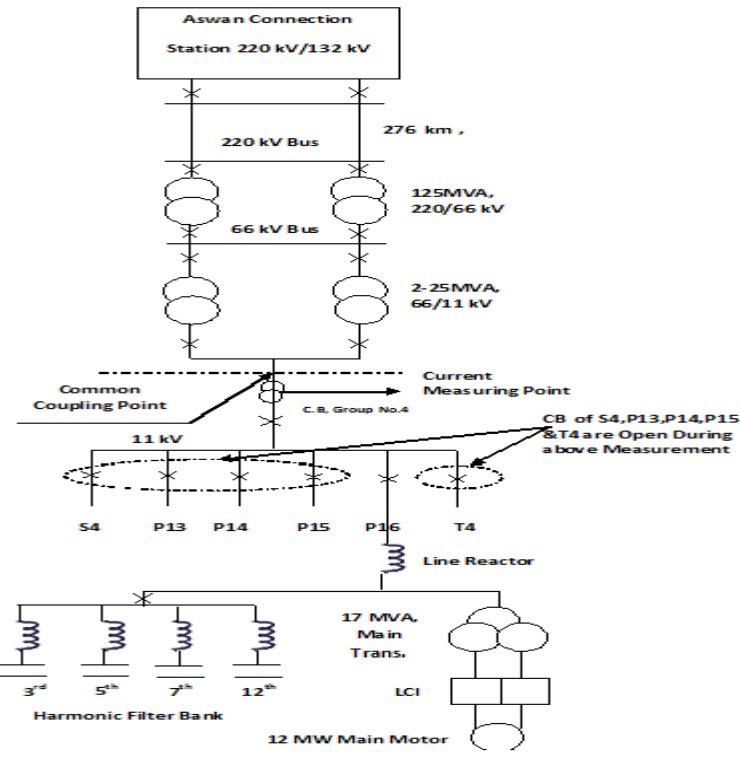

Fig. 3. Single line diagram of Toshka pimping station

TABLE III. HARMONICS MEASUREMENT WITH FILTER

\begin{tabular}{|c|c|c|c|c|}
\hline H & $\begin{array}{l}\mathbf{I}_{\mathrm{H}} \% \\
\text { fund }\end{array}$ & $\mathbf{I}_{\mathrm{H}}$ & $\mathbf{I}_{\mathbf{h}}=\mathbf{I}_{\mathbf{H}} / \mathbf{I}_{\mathrm{rms}}$ & $\mathbf{H}^{2 *}\left(\mathbf{I}_{h}\right)^{2}$ \\
\hline 1 & 100 & 1 & 0.996197 & 0.992408 \\
\hline 3 & 0.36702 & 0.0036702 & 0.003656 & 0.00012 \\
\hline 5 & 0.45481 & 0.0045481 & 0.004531 & 0.000513 \\
\hline 7 & 0.68039 & 0.0068039 & 0.006778 & 0.002251 \\
\hline 9 & 0.30952 & 0.0030952 & 0.003083 & 0.00077 \\
\hline 11 & 0.011008 & 0.00011008 & 0.00011 & $1.46 \mathrm{E}-06$ \\
\hline 13 & 5.501 & 0.05501 & 0.054801 & 0.507528 \\
\hline 15 & 0.12257 & 0.0012257 & 0.001221 & 0.000335 \\
\hline 17 & 0.19933 & 0.0019933 & 0.001986 & 0.00114 \\
\hline 19 & 0.26443 & 0.0026443 & 0.002634 & 0.002505 \\
\hline 21 & 0.19914 & 0.0019914 & 0.001984 & 0.001736 \\
\hline 23 & 4.4975 & 0.044975 & 0.044804 & 1.061911 \\
\hline 25 & 3.1756 & 0.031756 & 0.031635 & 0.625492 \\
\hline 27 & 0.14193 & 0.0014193 & 0.001414 & 0.001457 \\
\hline 29 & 0.21729 & 0.0021729 & 0.002165 & 0.003941 \\
\hline 31 & 0.21076 & 0.0021076 & 0.0021 & 0.004236 \\
\hline 33 & 0.15327 & 0.0015327 & 0.001527 & 0.002539 \\
\hline 35 & 2.6503 & 0.026503 & 0.026402 & 0.853918 \\
\hline 37 & 2.0062 & 0.020062 & 0.019986 & 0.546817 \\
\hline 39 & 0.13907 & 0.0013907 & 0.001385 & 0.002919 \\
\hline 41 & 0.21042 & 0.0021042 & 0.002096 & 0.007386 \\
\hline 43 & 0.17302 & 0.0017302 & 0.001724 & 0.005493 \\
\hline 45 & 0.12539 & 0.0012539 & 0.001249 & 0.00316 \\
\hline 47 & 1.4933 & 0.014933 & 0.014876 & 0.488855 \\
\hline 49 & 1.1575 & 0.011575 & 0.011531 & 0.319245 \\
\hline$\sum$ & & & $K=$ & 5.436679 \\
\hline
\end{tabular}




\section{Modeling of Toshka pumping station}

Toshka pumping station consists of four groups and each group contains six synchronous motors. The simulation model is consisted of the Aswan connection station $132 / 220 \mathrm{kV}$, two transmission lines $220 \mathrm{kV}$ (distance $276 \mathrm{~km}$ ), two transformers $125 \mathrm{MVA}, 220 / 66 \mathrm{kV}$ and two transformers $25 \mathrm{MVA}, 66 / 11 \mathrm{kV}$. Figure 4 shows the model of the pumping station, transmission lines and the power transformers. Figure 5 shows the control and drive circuits for the synchronous motor.

\section{Results}

The modeling results are obtained on the output of the $66 / 11 \mathrm{kV}, 25 \mathrm{MVA}$ transformer for the following two cases

\section{Case (1) without using harmonics filter:}

Figures 6-9 show voltage and current (phase and 3-phase) at low tension of 25MVA $66 / 11 \mathrm{kV}$ transformer.

Figures 10-11 show the frequency response characteristics without harmonic filter for voltage and current respectively. The harmonics of currents and voltages are listed in Table IV. The 5th, 7th and 11th harmonics exceeded the limits recommended by IEEE-519 [9]

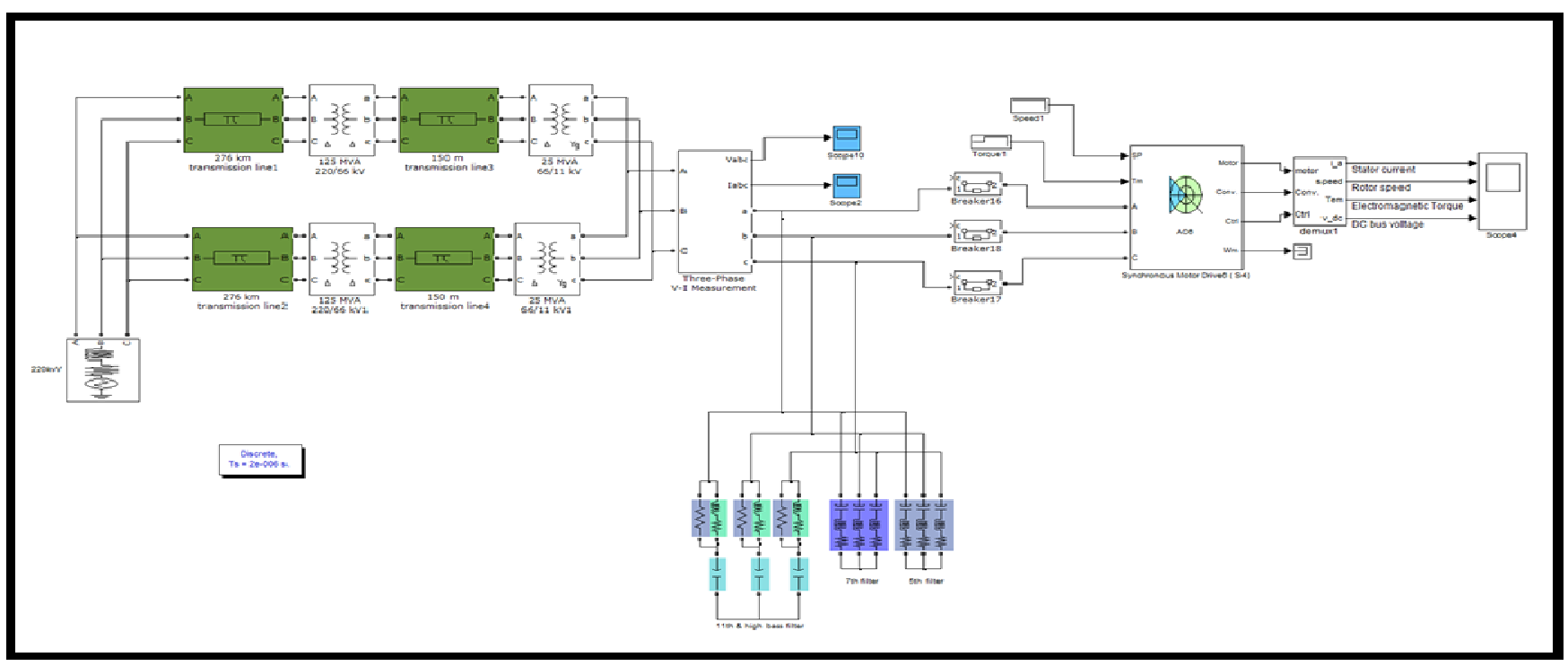

Fig. 4. Modeling of Toshka Pumping Station, transmission lines and the power transformers

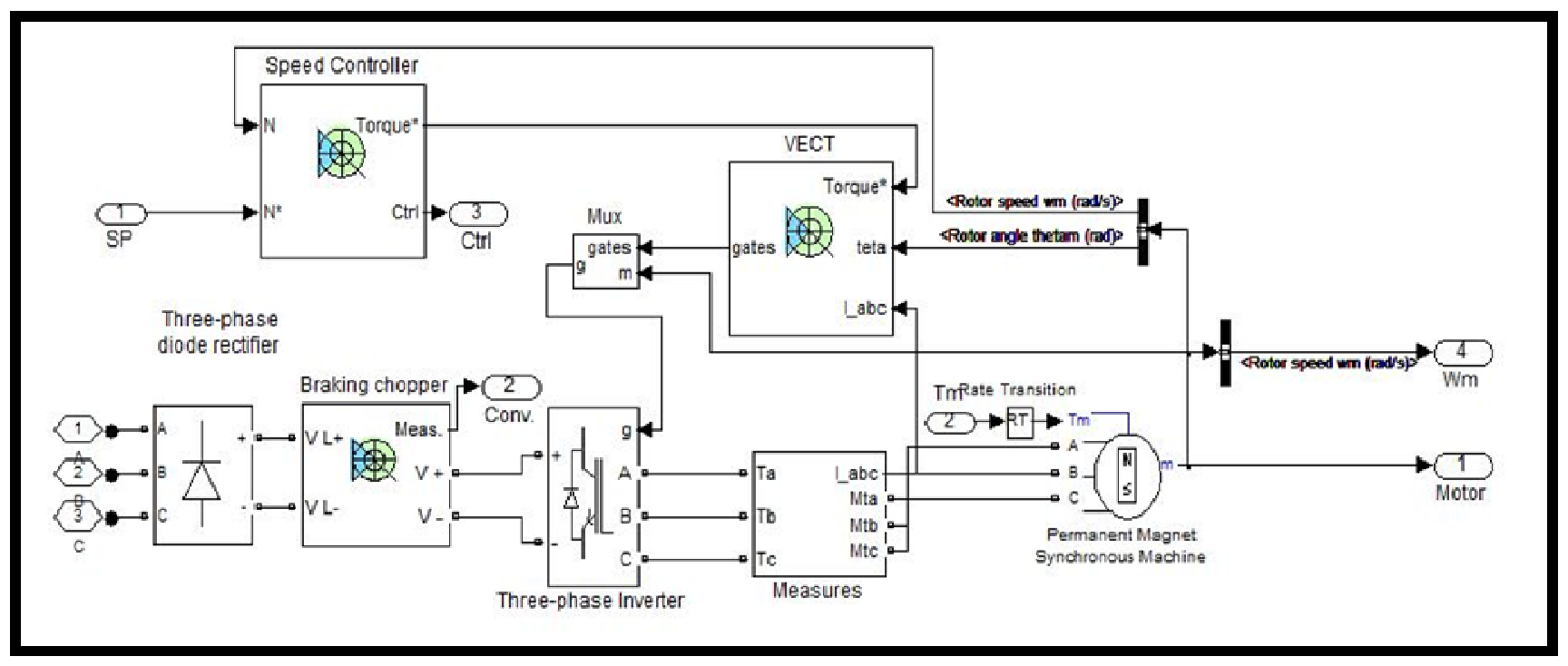

Fig. 5. Control and drive circuit for the synchronous motor 


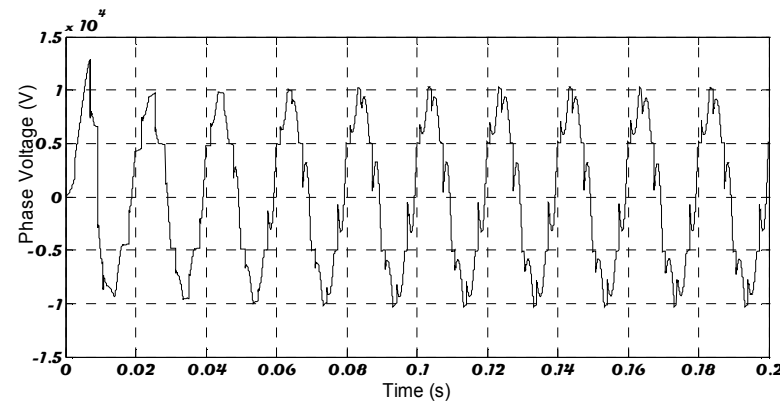

Fig. 6. Phase voltage at low tension side of 25MVA $66 / 11 \mathrm{kV}$ transformer without harmonic filter

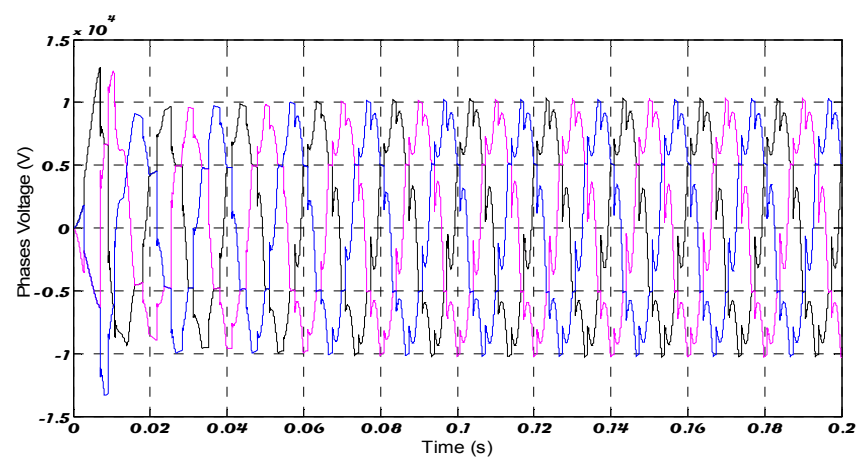

Fig. 7. 3-Phase voltage at low tension side of 25MVA 66/11KV transformer without harmonic filter

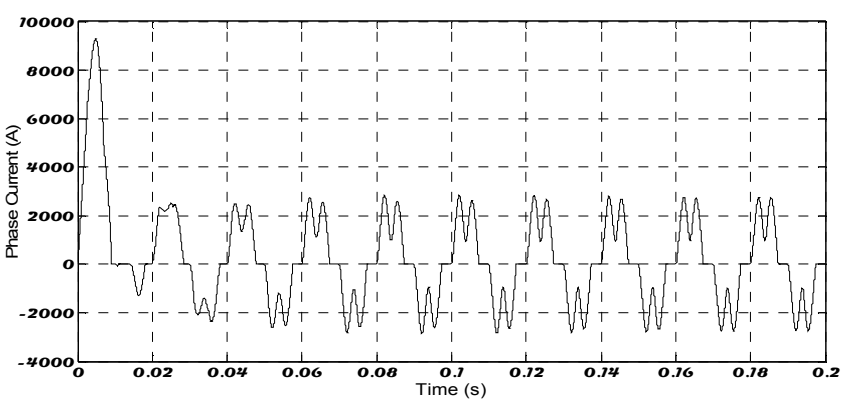

Fig. 8. Phase current at low tension side of 25MVA 66/11KV transformer (without harmonic filter)

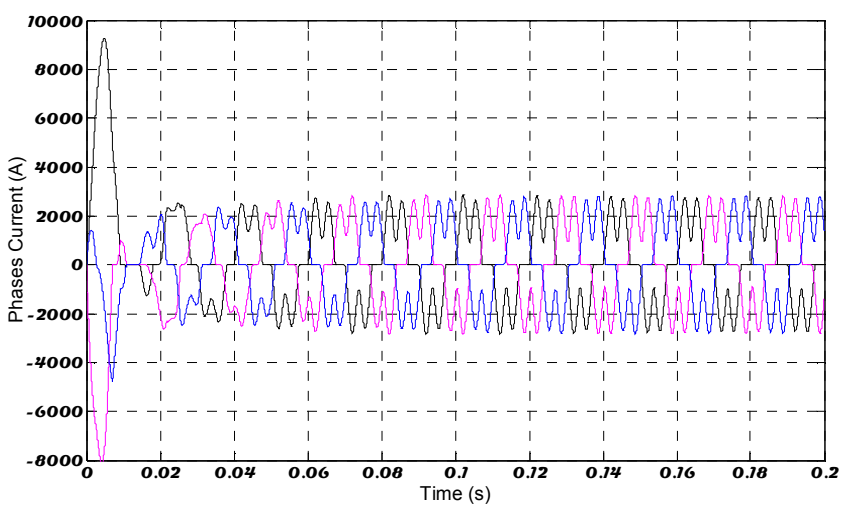

Fig. 9. 3-Phase current at low tension side of 25MVA 66/11KV transformer without harmonic filter
TABLE IV. THD FOR VOLTAGE AND CURRENT WITHOUT USING FILTER

\begin{tabular}{|c|c|c|}
\hline Harmonic order & $\begin{array}{c}\text { Harmonic voltage } \\
\text { \% If }\end{array}$ & $\begin{array}{c}\text { Harmonic current } \\
\text { \% If }\end{array}$ \\
\hline 3 & 1.72 & 2.92 \\
\hline 5 & 9.29 & 41.11 \\
\hline 7 & 11.49 & 11.29 \\
\hline 11 & 6.17 & 3.53 \\
\hline THD & $17.64 \%$ & $42.93 \%$ \\
\hline
\end{tabular}
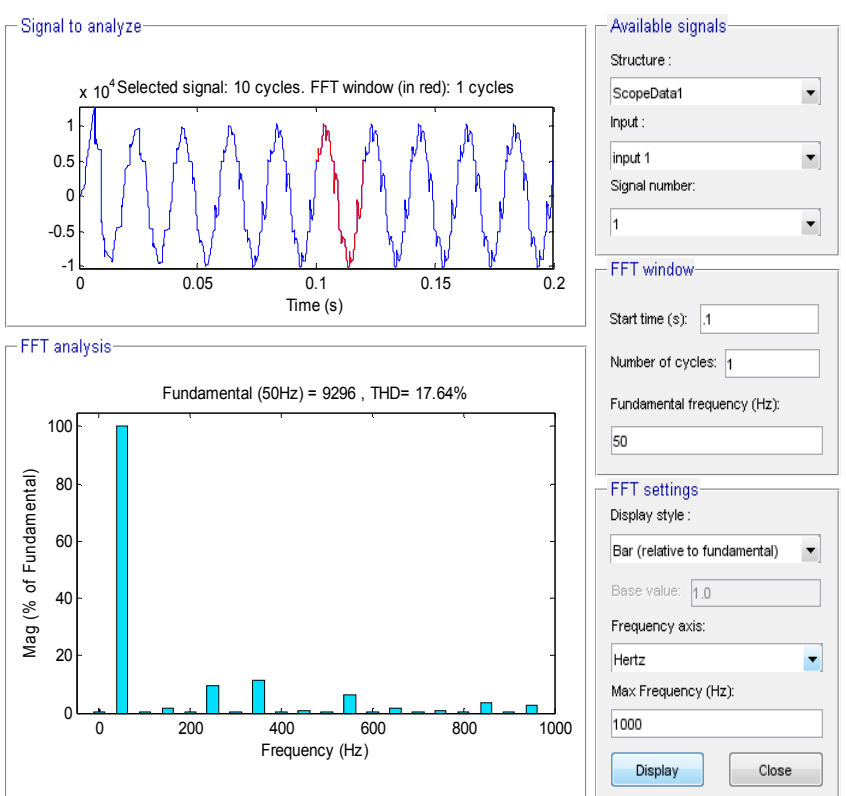

Fig. 10. Voltage and frequency response characteristics without harmonic filter

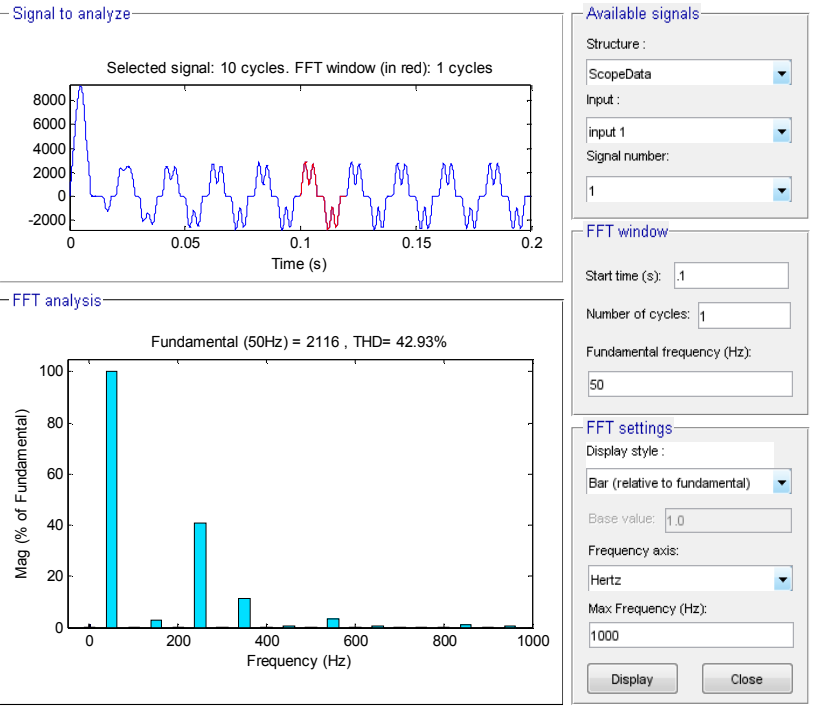

Fig. 11. Current and frequency response characteristics without harmonic filter

Case (2) by using harmonics filter

Figures 12-13 show 3-phase voltage and current at low tension of $25 \mathrm{MVA} 66 / 11 \mathrm{kV}$ transformer respectively with harmonic filter. Figures 14-15 show the frequency response characteristics when using harmonic filter for voltage and 
current respectively. The total harmonic distortion for current and voltage with and without the use of the harmonic filter is listed in Table V. The calculated K-factor for the simulated model with and without harmonic filter is shown in Table V. The K-factor without the use of the harmonic filter is 5.1497 which is five times greater than the K-factor calculated when using the harmonic filter. Therefore, when a harmonic filter is employed, the $\mathrm{K}$-factor rating used is $\mathrm{K} 1$ or $\mathrm{K} 4$ whereas a $\mathrm{K}$ factor rating of $\mathrm{K} 7$ is used when a harmonic filter is not employed. The K-factor calculated from the measured values taken from the station is approximately equal to the calculated values of the simulated model.

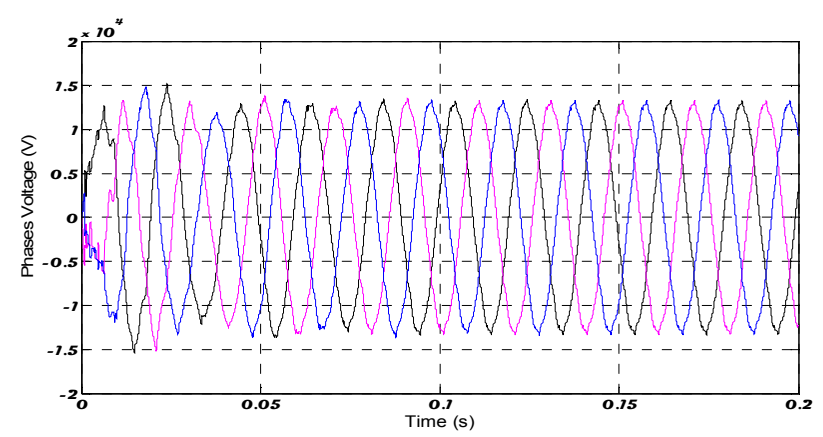

Fig. 12. 3-Phase voltage at low tension side of 25MVA 66/11KV transformer with harmonic filter

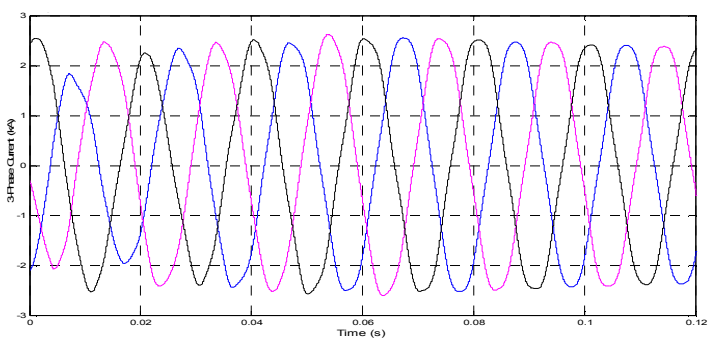

Fig. 13. 3-Phase Current at low tension side of 25MVA 66/11KV transformer with harmonic filter
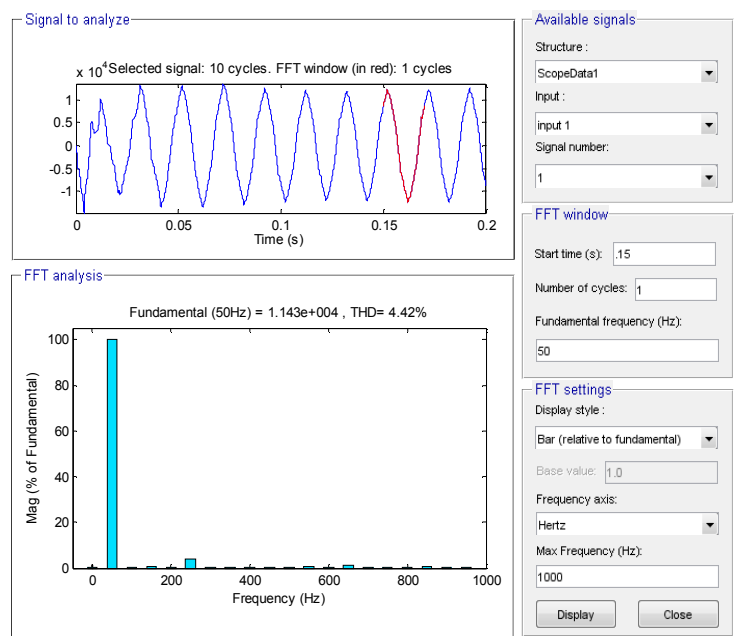

Fig. 14. Voltage and frequency response characteristics with harmonic filter
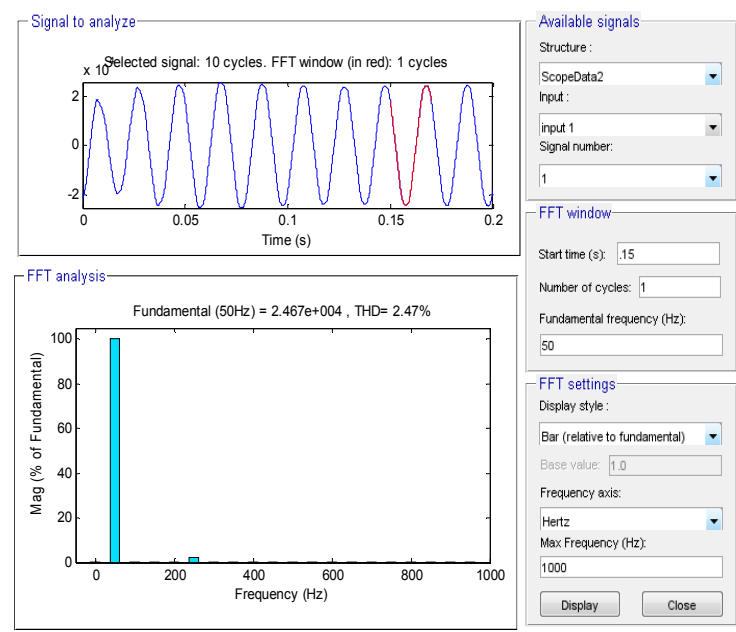

Fig. 15. Current and frequency response characteristics with harmonic filter

TABLE V. K-FACTOR AND THD FOR VOLTAGE AND CURRENT

\begin{tabular}{|c|c|c|c|c|}
\hline & \multicolumn{2}{|c|}{ Without Harmonic Filter } & \multicolumn{2}{c|}{ With Harmonic Filter } \\
\hline THDu\% & THDI\% & THDu\% & THDI\% \\
\hline 17.64 & 42.93 & 4.42 & 2.47 \\
\hline \multicolumn{2}{|c|}{ IEEE-519 recommended Limit } & \multicolumn{2}{|c|}{$5 \%$} & $5 \%$ \\
\hline $\begin{array}{c}\text { K-factor } \\
\text { From measured values }\end{array}$ & 5.436679 & \multicolumn{2}{|c|}{1.200575} \\
\hline $\begin{array}{c}\text { K-factor } \\
\text { From modeling }\end{array}$ & 5.1497 & \multicolumn{2}{|c|}{1.0147} \\
\hline
\end{tabular}

\section{CONCLUSION}

In this paper a study of $\mathrm{K}$-factor power transformer characteristics is presented. A case study (Toshka pumping station) is simulated with the use of Matlab Simulink. The total harmonics distortion at the output of 25MVA, 66/11KV transformer with and without harmonic filter is calculated. Measured harmonics current and calculated K-factors with and without filters are in agreement with the results obtained by the suggested model.

\section{REFERENCES}

[1] I. Daut, H. S. Syafruddin, H. Haziah "The effects of harmonic components on transformer losses of sinusoidal source supplying nonlinear loads", American Journal of Applied Sciences, Vol. 3, No. 12, pp. 2131-2133, 2006.

[2] R. N. Jayasinghe, "Power system harmonic effects on distribution transformers and new design considerations for K-factor transformers" IEE Sri Lanka Annual Sessions, 2003.

[3] I. A. Maswood, "Harmonics, sources, effects and mitigation techniques" Second Intl. Conf. on Electrical and Computer Engineering, ICECE, Dhaka, Bangladeh, 2002.

[4] T. M Salih, "The effect of the harmonic components upon transformer active losses in case of (non) sinusoidal sources and (non) linear loads", IEEE International Conference on Industrial Technology, Vol. 2, 2000.

[5] G. W. Massey, "Estimation methods for power system harmonic effects on power distribution transformers", IEEE Trans. Industry Appl., Vol. 30, No. 2, pp. 485 - 489, 1994.

[6] Computer Business Equipment Manufacturers Association (CBEMA) "Three-phase power source overloading caused by small computers and electronic office equipment", ESC-3 Information Letter, 1987. 
[7] T. M Gruzs, "A Survey of neutral currents in three-phase computer power systems", IEEE Trans. on Industry Applications, Vol. 26, No.4, pp. $719-725,1990$.

[8] ANSI/IEEE C57.110 "Recommended practice for establishing transformer capability when supplying non-sinusoidal load currents", 1998.

[9] IEEE standard, 519 "Recommended practices and requirements for harmonic control in electrical power systems", 1992

[10] Underwriters Laboratories, UL1561 "Proposed requirements and proposed effective dates for the first edition of the standard for dry-type general purpose and power transformers", Santa Clara CA, 1991.

[11] D. Yildirim, E. F. Fuchs, "Measured transformer de-rating \& comparison with harmonic loss factor (FHL) approach", IEEE Transactions on Power Delivery, Vol. 15, No. 1, pp. 186-191, 2000.

[12] S. N. Makarov, A. E. Emanuel, "Corrected harmonic loss factor for transformers supplying non-sinusoidal load currents", 9th International Conference on Harmonics and Quality of Power, Vol. 1, pp. 87 - 90, 2000.

[13] Tao Shun, Xiao Xiangning, "Comparing transformer de-rating computed using the harmonic loss factor FHL and K-factor", 3rd International Conference on Electric Utility Deregulation and Restructuring and Power Technologies, pp. 1631 - 1634, Nanjing China, 2008.

[14] http://www.federalpacific.com/university/kfactor/kfactor.html

[15] Copper Development Association, "Harmonics, transformers and Kfactors", CDA Publication 144, 2000.

[16] http://www.powertransformer.us/federalpacifickfactor transformers.htm

[17] N. M. Abdelsalam, M. M. Abdelaziz, "Toshka project electrical power demand", 12th International Water Technology Conference, IWTC12 pp. 503 - 517, Alexandria, Egypt, 2008.

[18] Consulting Services for the South of Egypt Development Project, "Water management plan", Technical Assistance for Toshka Project, Vol. 3, 2004. 